\title{
Should the terms 'basal taxon' and 'transitional taxon' be extinguished from cladistic studies with extinct organisms?
}

\author{
Mario Bronzati
}

\begin{abstract}
The terms basal and transitional have been widely adopted to designate the condition or nature of taxa in a phylogenetic context. Because they are taken as informative, some authors might even use these terms in an attempt to enhance the perceived value of a particular fossil discovery. Nevertheless, basal and transitional are most of the times erroneously or inconsistently applied, or are redundant to the arguments or quality of a scientific work and/or condition of taxa. In some cases, they can lead to the idea that the evolution of a lineage happened toward a specific group, in a mode of teleological reasoning. Here I illustrate problematic issues that can arise from this varied use of both terms. Finally, it is shown how statements that are in accordance with the cladistic method can substitute both terms in order to avoid pointless or misleading information.
\end{abstract}

Mario Bronzati. Bayerische Staatssammlung für Paläontologie und Geologie. Richard-Wagner-Str. 10, 80333, Munich, Germany, and Department of Earth and Enviromental Sciences, Ludwig-MaximiliansUniversität, Richard-Wagner-Str. 10, 80333, Munich, Germany. mariobronzati@gmail.com; m.bronzati@Irz.uni-muenchen.de

Keywords: Phylogenetics; Vertebrate Palaeontology; Dinosauria; Sauropodomorpha; Evolution

\section{INTRODUCTION}

The terms 'basal taxon/form' (e.g., Martinez et al., 2011; Sues et al., 2011; Xu et al., 2014) and 'transitional taxon/form' (e.g., Daeschler et al., 2006; Longrich et al., 2012; Pinheiro et al., 2016) have been widely adopted in cladistic studies in vertebrate palaeontology. These terms are taken as informative and sometimes applied in an attempt to increase the putative impact of research when communicating the importance of specimens or taxa. For example, "Coniophis therefore represents a transitional snake, combining a snake-like body and a lizard-like head" (Longrich et al., 2012); "new discoveries of transitional fossils such as Tiktaalik make the distinction 
between fish and the earliest tetrapods increasingly difficult to draw" (Daeschler et al., 2006); "Teyujagua paradoxa, transitional in morphology between archosauriforms and more primitive reptiles" (Pinheiro et al., 2016); "the result of analysis of that second matrix places Chongmingia as the most basal bird other than the iconic 'Urvogel' Archaeopteryx (Wang et al., 2016); "despite its basal position in early avian evolution, the advanced features of the pectoral girdle and the carpal trochlea of the carpometacarpus of Jeholornis indicate the capability of powerful flight" (Zhou and Zhang, 2002); represent only some of several uses of the terms in order to tentatively capture the phylogenetic context of particular taxa. As such, it can be seen that these are often highly attractive expressions to journals and for broader science communication activities. However, their employment in the scientific literature appears to be inconsistent and often applied with insufficient rationale.

'Tree thinking' has been much debated in the literature often regarding extant taxa (e.g., Krell and Cranston, 2004; Baum et al., 2005; Crisp and Cook, 2005; Omland et al., 2008: Zachos, 2016), but the lack of studies dealing with the question of extinct taxa might explain the persistence of incorrect terminology application in the field of palaeontology. Here, I use the example of the sauropodomorph dinosaurs to better illustrate how the terms 'basal' and 'transitional' have been variably applied in the field of vertebrate palaeontology. In this context, it is explained what taxa have been referred to as 'basal' sauropodomorphs and why they have often been called 'transitional' in this regard. Finally, it is discussed if the application of these terms makes sense in phylogenetic studies of other groups.

\section{What Are the So-called 'Basal' Sauropodomorphs?}

Sauropodomorpha, one of the three main established dinosaur lineages (Langer et al., 2010), has a fossil record extending from the Late Triassic (Carnian) till the K/Pg mass extinction event (Figure 1). The earliest representatives (Carnian - c. $230 \mathrm{Ma}$ ) of Sauropodomorpha are probably bipedal (or facultatively bipedal), omnivorous and fau-

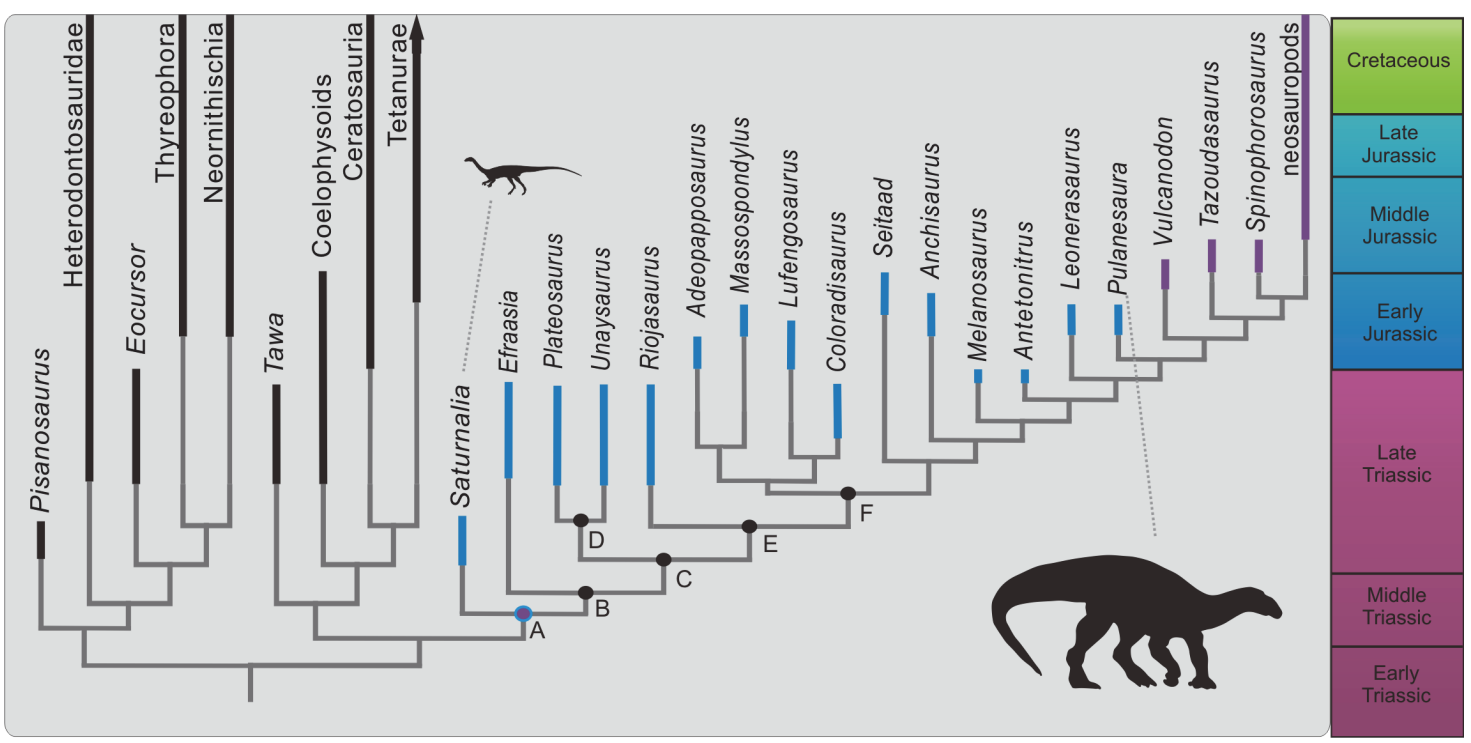

FIGURE 1. Simplified cladogram showing the relationships of the three main lineages of dinosaurs with focus on Sauropodomorpha. Letters $A$ - $F$ are related to clades treated in the main text. The assumed ages for the taxa of the tree are represented by rectangles thicker than other branches. Cladogenetic events (dichotomies) are not calibrated against geological time. Ornithischia is represented by the following taxa: Pisanosaurus, Heterodontosauridae, Eocursor, Thyreophora, Neornithischia. Theropoda is represented by the following taxa: Tawa, coelophysoids, Ceratosauria, Tetanurae. All other taxa represent Sauropodomorpha (here following the definition of Galton and Upchurch, 2004). Sauropoda (here following the definition of Salgado et al., 1997) is represented by Vulcanodon, Tazoudasaurus, Spinophorosaurus, Neosauropoda. 
nivorous (Cabreira et al., 2016), and small-bodied, not reaching more than $2 \mathrm{~m}$ in length (Langer et al., 2010). On the other hand, the sauropods are the largest terrestrial animals that have ever inhabited the Earth (Sander et al., 2011), and their long necks, quadrupedal stance and gigantic body size represents a very distinct morphological body plan in comparison to the earliest sauropodomorphs.

'Prosauropoda' was once thought to be a monophyletic group encompassing Late Triassic and Early to Middle Jurassic sauropodomorphs, and the sister group of Sauropoda (Galton and Upchurch, 2004). However, more recent studies have pointed out that the most likely scenario concerning the evolution of the Sauropodomorpha lineage is that the classical 'prosauropods' represent a paraphyletic assemblage of taxa in relation to Sauropoda (see Peyre de Fabrègues et al., 2015 for historical discussion on this issue). This paraphyletic condition of 'Prosauropoda' is the root cause of the association of the term 'basal' sauropodomorph to refer to sauropodomorph taxa that fall outside of the main Sauropoda clade (Otero and Salgado, 2015). This is probably due to the consequential interpretation of non-sauropod sauropodomorphs as being closer to the root of Sauropodomorpha than sauropods.

\section{'Basal Sauropodomorphs' as Transitional Forms}

The recognition of 'Prosauropoda' (the so called 'basal sauropodomorphs') as paraphyletic in relation to sauropods triggered the idea that these taxa were therefore transitional forms with respect to the Sauropodomorpha lineage (Gauthier, 1986). For instance, Sereno (1989) argued against this transitional view not because of problems related to the term itself (see the discussion in that study), but because the results of his analysis depicted 'Prosauropoda' as monophyletic, sister-group of Sauropoda. This probably reflects the problem of visualising cladograms as ladders of progress (Zachos, 2016), and the use of transitional in these cases might be the result of something visual, but has no evolutionary significance. The resulting topologies of phylogenetic analyses are usually represented by ladderized (pectinate) trees (i.e., a tree which has the species-poor sister group always represented in the same side of a dichotomy). In the case of sauropodomorphs, the 'basal' sauropodomorphs are typically represented in the left/up side of the tree and taxa, and taxa nested within Sauropoda are presented on the right/down side of the tree (see Figure 1). Furthermore, discoveries of non-sauropodan sauropodomorphs exhibiting features once thought to be exclusive of sauropods contributes to postulations that these animals are transitional between early sauropodomorphs from the Carnian and later sauropods (e.g., Yates et al., 2010; McPhee et al., 2014).

\section{ARE THERE 'BASAL' AND 'TRANSITIONAL' TAXA IN THE FOSSIL RECORD?}

\section{Palaeontology and Neontology: Where Are the Differences?}

Previous studies (Krell and Cranston, 2004; Crisp and Cook, 2005; Zachos, 2016) have emphasized that all OTUs of a cladogram containing solely living taxa are equally far away from the root, because they all co-exist in the same time. But what about the relationship between time and 'basal forms' in the context of a cladrogram that contains extinct taxa? The $y$-axis of a cladogram has time as a component (Hennig, 1965; Zachos 2016) once a root is assigned to it (Brower and de Pinna, 2012). In this way, using the phylogeny of Figure 1 it is correct to state that the node $A$ is 'closer' to the base than the node $B$, as it is older. It is also possible to state that the branches leading to nodes $D$ and $E$ originated at the same age. However, the taxa descending from the node $A$ in both sides of the tree have specific ages assigned to them (note that these are the minimum ages; and that the minimum age can change if an older fossil referred to a particular taxon is found). In the specific case of Saturnalia and Efraasia, the former is older than the latter. So, if time is the unit assigned to the y-axis, Saturnalia is closer to the basis than Efraasia (Saturnalia is 'basal' to Efraasia). Coloradisaurus is 
also 'closer' to node $F$, than are other taxa within the clade delimited by this node. But this statement is only related to the age of fossils and not to positions in the tree. Thus, even if Saturnalia were recovered among sauropods in a hypothetical analysis, it would still be older, and then closer to the root, than Efraasia.

Regarding the age of taxa, one possibility to refer to a particular assemblage is to use terms such as 'early' or 'late', rather than basal. For example, this has been done for dinosaurs as a whole, with the term 'early dinosaurs' being used to refer to the oldest representatives of the lineage (e.g., Langer and Benton, 2006). However, as there are no pre-defined boundaries for these terms, the best approach might be to always use a specific time frame, or to use terms like 'early' and 'late' in an explicit comparative framework. Some possibilities include "the Carnian sauropodomorph Saturnalia and Buriolestes have teeth with small serrations, whereas later sauropodomorphs such as Efraasia and Plateosaurus exhibit coarser denticles"; and "differently from the gigantic sauropods, the earliest sauropodomorphs from the Carnian were small animals". The usage of such a framework will avoid any ambiguity between scientists, and will also benefit the clarity of communication to non-scientific audiences by explicitly incorporating the concept of time in the evolutionary process (see below). It is, however, important to stress out that taxa from the same period of time (e.g., Carnian, Middle Jurassic, Cenozoic) do not necessarily compose a monophyletic group, and therefore comparisons using time as a reference for an assemblage of taxa should be aware of the limitations of the term. Yet, in a cladogram containing extinct taxa, the oldest taxon is not necessarily associated to the oldest cladogenetic events of the tree, and therefore 'basal taxon' and early taxon cannot be always interchangeably used.

\section{'Basal' Sauropodomorphs Versus Non-sauropodan Sauropodomorphs}

As observed by Otero and Salgado (2015), the term 'basal sauropodomorphs' has been widely used interchangeably with 'non-sauropodan sauropodomorphs' in the published research literature. At first glance, applying the term in such a way seems to be a good alternative, as the phylogenetic context is clearly defined. Indeed, it might seem semantically easier to refer to a taxon as a 'basal sauropodomorph' instead of a non-sauropod sauropodomorph, and as shown both are often used interchangeably (see Otero and Salgado, 2015; Peyre de Fabrègues et al., 2015). Nevertheless, even if researchers think that these terms are clear, different people certainly have different assumptions of what a 'basal' taxon is. For instance, is a 'basal' sauropodomorph a non-sauropodiform (i.e., a clade within Sauropodomorpha that includes Sauropoda see e.g., McPhee et al. (2014) for the definition of Sauropodofirom) sauropodomorph or a non-sauropodan sauropodomorph? Furthermore, the use of 'basal', in this context, is inaccurate. As 'basal' is a relative term regarding the base of the tree, which in turn corresponds to the root of rooted trees (Krell and Cranston, 2004; Crisp and Cook, 2005), it is erroneous to use it here to mean not belonging to a clade.

How should the 'basal forms' be treated in this case? When the term 'basal' is used to refer to a paraphyletic assemblage of taxa (as 'basal sauropodomorphs'), there might not actually be a single correct way to refer to it - it is also important to stress here that we cannot give formal taxonomic recognition to 'prosauropods' or non-sauropodan sauropodomorphs, simply because they are not monophyletic (Schmidt-Lebuhn, 2012). In this way, referring to these assemblages of taxa can be done as, for example, "all the non-sauropodan sauropodomorph lineages vanished before the end of the Middle Jurassic," or "so far, no fossils of non-sauropodan sauropodomorph lineages have been discovered in Mongolia." This nomenclature has value in that it defines bounds for the phylogenetic context of all the monophyletic clades (separately, not as an unit) within one particular region of the tree, and therefore should be used instead of terms like 'basal', which can even carry misleading assumptions (see below the discussion regarding basal taxa and plesiomorphic character states). This is already the case for dinosaurs, as the most common way now to refer to the famous 
extinct relatives of birds is to call them 'non-avian dinosaurs' (see e.g., Lloyd et al., 2008). A desirable aspect of this terminology instead of the term 'basal' is that it precisely describes the hierarchical system advocated in phylogenetics (Hennig, 1966) and is probably clearer for communication with non-specialists.

\section{Basal Taxa Are Closer to the Root of the Tree: But How to Measure It?}

The idea of basal taxa is probably related to an assumption that basal forms are 'close' to the root of the tree or to the node corresponding to the group being dealt with (e.g., Langer et al., 2010; Martinez et al., 2011; Wang et al., 2016). In the case of sauropodomorph dinosaurs, one can argue that some 'prosauropods' are 'closer' to the node corresponding to Sauropodomorpha, and therefore in this case they are regarded as 'basal sauropodomorphs'. This association between proximity to the root and basal forms has even led authors to consider some taxa as the most basal representative of Sauropodomorpha (e.g., Langer et al., 2010; Cabreira et al., 2016). The most likely scenario here is that authors assume that the number of nodes between a taxon and the root (or clade of interest) gives a 'measurement' of how basal it is. However, a single example can demonstrate how problematic (or pointless) this approach is. In the topology of Figure 1, there is no node between Saturnalia and the node encompassing all the sauropodomorphs used as terminal taxa (i.e., node A of figure 1), and, there is one node (i.e., node B of Figure 1) between node A and Efraasia. Nevertheless, if two new taxa are included in a different analysis, and these two taxa are found to be closer to Saturnalia than to Efraasia (Figure 2), there can be two nodes between Saturnalia and the node of the clade containing all the sauropodomorphs (i.e., node $\mathrm{C}$ of Figure 2 ), whereas only one between this node and Efraasia (Figure 2). In the latter case, using the number of nodes to calculate how basal a taxon is, Efraasia would be considered 'more basal' than Saturnalia, even with Efraasia belonging to a less-inclusive clade with later sauropodomorphs (including sauropods) that does not include Saturnalia.

The number of nodes between a terminal taxon and the root of the tree does not tell us how far it is from the root (i.e., if it is a basal taxon or not). The number of nodes can be related, among other things, to the diversity of a clade. More cladogenetic events (i.e., more nodes) mean more speciation and more diversity (Tarver and Donoghue, 2011), and therefore tell us more about evolutionary mode than phylogenetic sta-

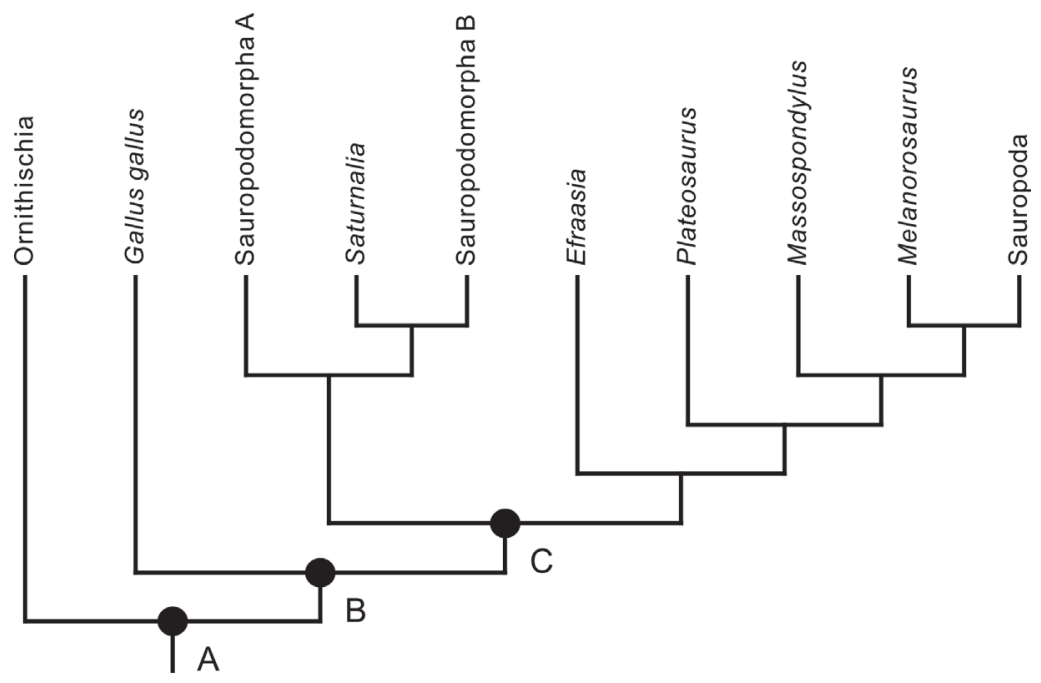

FIGURE 2. Simplified version of the cladogram of Figure 1 showing the relationships of the three main lineages of dinosaurs with focus on Sauropodomorpha. 'Sauropodomorpha A' and 'Sauropodomorpha B' represent two hypothetical taxa that are more closely related to Saturnalia than to Sauropoda. Ornithischia is represented by a single terminal taxon and Theropoda is represented by the living bird Gallus gallus. 
tus. The number of nodes can also be related to the ingroup sampling. For example, in a cladogram where theropods are represented solely by a living bird alongside with all the ornithischians and sauropodomorphs known so far (see Figure 2), the living bird Gallus gallus (the red junglefowl) would be only a few nodes away from the base of the clade encompassing all the dinosaurs (node A). In this case, we would hope that no one would suggest that the bird is a 'basal' dinosaur or a 'basal' saurischian based on the number of intervening nodes to the root. Finally, the existence of a branch leading to taxa (or to a taxon) that are much younger than its sister group can mean, among other things, that there are still unknown taxa that are more closely related to the taxa (or taxon) descending from this branch than to any other one in the tree; or that the ingroup is not well sampled (as in the case of the living bird representing theropods).

The discussion regarding the number of nodes and the 'apparent' distance to the root can also be used to discuss aspects of another term that has been applied in studies dealing with extinct taxa, early divergent (e.g., Zanno et al., 2015; Griffin and Nesbitt, 2016). As the term implies, it is typically applied to refer to lineages that apparently diverged earlier in relation to the others depicted in a cladogram. Using the example of the cladogram in Figure 2, in the context of the clade defined by node A, Gallus gallus could be interpreted as having diverged earlier than Saturnalia because there are fewer nodes between Gallus gallus and node A, than there are nodes between Saturnalia and node A. Nevertheless, this interpretation is problematic because it compares things that are not comparable phylogenetically. Such comparisons only apply to sistergroups (Crisp and Cook, 2005; Zachos, 2016), and in this case, 'the lineage containing Gallus gallus but not sauropodomorphs' diverged at the same time of the 'lineage containing all the sauropodomorphs', which in turn includes Saturnalia. Yet, the cladogram also indicates that the 'lineage containing Gallus gallus but not sauropodomorphs' diverged from 'the lineage containing only sauropodomorphs' earlier than 'the lineage containing Saturnalia + Sauropodomorpha A + Sauropodomorpha B but not the other sauropodomorphs' diverged from 'the lineage containing Efraasia + Sauropoda but not Saturnalia'. However, the taxon Gallus gallus did not diverge earlier than the taxon Saturnalia. Time of divergence of Saturnalia and Gallus gallus is only associated to the age of the taxa, but not to their relative position in the cladogram.

Other aspects of the usage of the term 'basal' have already been addressed in other publications in the context of living species (Krell and Cranston, 2004; Crisp and Cook, 2005; Zachos, 2016). As mentioned in these studies, it is not terminal taxa (or OTUs - Operational Taxonomical Units) that can be 'more basal' in relation to other terminal taxa, but the nodes (i.e., hypothetical ancestors) of the tree in relation to other nodes (Crisp and Cook, 2005; Zachos, 2016). Thus, in the tree topology (Figure 1), it is the node corresponding to the ancestor of the less inclusive clade including Saturnalia and neosauropods (node $A$ ) that is basal in relation to the node representing the ancestor of the less inclusive clade containing Efraasia and neosauropods (node B). Saturnalia is not a basal sauropodomorph in relation to Efraasia, neither even in relation to Sauropoda, and nor is Saturnalia the basal most taxon of Sauropodomorpha because of its position in the cladogram. Still, Saturnalia and Efraasia are consecutive sister-groups of less inclusive clades within Sauropodomorpha, clade B (node B and all species descending from it) and clade $C$ (node $C$ and all species descending from it), respectively. The clade $D$ (node $D$ and all species descending from it) is not more basal than the clade $F$ (node $F$ and all species descending from it). Moreover, clades defined by nodes $D$ and $F$ are not sister-groups, and therefore no direct comparison can be made between them alone in terms of relationships between each other (Hennig, 1966). This is important to stress because many authors claim that basal is related to something graphical instead of evolutionary or phylogenetic (see also Crisp and Cook, 2005). The resulting tree is an arrangement of organisms in a phylogenetic (or hierarchical) system of progressively less/more inclusive clades and its respective sister groups (Hennig, 1966). Thus, enunciating relationships on the basis of a sister group 
relationship is the proper way to describe phylogenetic relationships in a cladogram (Zachos, 2016). For instance, the most 'basal' taxon is actually the sister group of all other taxa within that lineage; 'basal lineages' are consecutive sister groups of progressively less inclusive clades.

\section{Do 'Basal' Taxa Have More Plesiomorphic Traits?}

The idea of 'basal' taxon can be accompanied by the false notion that the 'most basal taxon' exhibits less apomorphic character states than the other taxa (see e.g., Crisp and Cook, 2005). However, despite the possibility of having such scenario, it is not true for all the cases. This can be demonstrated using the example of Figure 3. A single most parsimonious tree (MPT) is found when the data matrix is analysed using parsimony. Using the notion of basal as discussed above, one could argue that taxon $A$ is the 'basal most' taxon of clade X. Nevertheless, in the context of clade X, taxon A has six apomorphic traits, whereas taxon $B$ has two, and taxa $C-F$ have four each. Thus, B-F are more closely related to each other than to $A$ because they share more apomorphies among them than any of them shares with $A$, but not because $A$ has fewer apomorphies in the context of the clade including A-F.

\section{Transitional Taxa: a Linear Way of Thinking About Evolution?}

The first question that probably comes to the mind after reading a sentence such as "a new transitional taxon is here presented" is: transitional between what? After all, this way of thinking makes no sense in the theoretical basis of biological evolution as understood nowadays because evolution has no goal (Laland et al., 2015). It also has no basis in a cladistic paradigm because trees are branching diagrams (Hennig, 1966), not ladders of progress (Zachos, 2016).

Two resulting lineages of a cladogenetic event (if dichotomous) exhibit similar character states for some of the characters, but each has a combination of plesiomorphic and apomorphic traits not observed in any other. It is important to stress that the absence of autapomorphies in taxa B (Figure 3) does not indicate that it is transitional

\begin{tabular}{|c|c|c|c|c|c|c|c|c|c|c|}
\cline { 2 - 11 } \multicolumn{1}{c|}{} & C1 & C2 & C3 & C4 & C5 & C6 & C7 & C8 & C9 & C10 \\
\hline Taxon Y & 0 & 0 & 0 & 0 & 0 & 0 & 0 & 0 & 0 & 0 \\
\hline Taxon A & 1 & 0 & 0 & 0 & 0 & 1 & 1 & 1 & 1 & 1 \\
\hline Taxon B & 1 & 1 & 0 & 0 & 0 & 0 & 0 & 0 & 0 & 0 \\
\hline Taxon C & 1 & 1 & 1 & 0 & 1 & 0 & 0 & 0 & 0 & 0 \\
\hline Taxon D & 1 & 1 & 1 & 0 & 1 & 0 & 0 & 0 & 0 & 0 \\
\hline Taxon E & 1 & 1 & 1 & 1 & 0 & 0 & 0 & 0 & 0 & 0 \\
\hline Taxon F & 1 & 1 & 1 & 1 & 0 & 0 & 0 & 0 & 0 & 0 \\
\hline
\end{tabular}

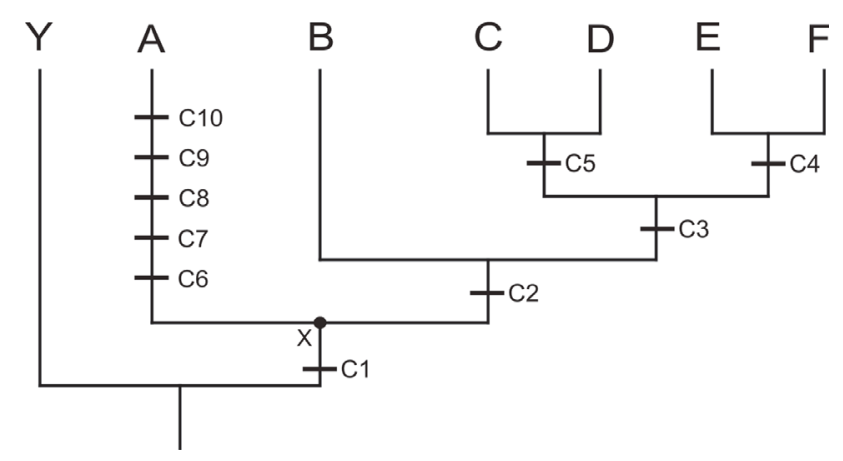

FIGURE 3. Hypothetical data matrix and the most parsimonious tree obtained when it is analysed using parsimony. 
between $\mathrm{A}$ and C-F. Firstly, this might be just a reflex of the lack of ability to translate different morphologies into phylogenetic characters. Furthermore, the study of living species shows us that even if there is no recognisable morphological difference between, they can differ in the genetic level. Using sauropodomorphs to illustrate that, we can consider taxa E-F as sauropods, and taxa A-D as non-sauropodan sauropodomorphs (Figure 3 ). This shows that some characteristics of non-sauropodan lineages (characters 5-10) are not present in sauropods. Thus, despite sharing some common ancestors, part of the evolutionary history of each lineage is independent from the others. In this way, Figure 3 highlights the problem of visualizing trees as ladders of progress because there is no directed evolution to a specific part of the cladogram. Diversification of lineages is a process through time with unpredictable paths. As a result, there is no stepwise evolution leading to any particular bauplan.

For Sauropodomorpha, the presence of some of the features found in all sauropods in other lineages outside the Sauropoda clade does not tell us that the non-sauropodan sauropodomorphs are transitional between the ancestor of Saruopodomorpha and sauropods. It only tells us that the evolution of these characters happened in a step-wise and/or mosaic fashion on the evolutionary history of the group. Any terminal taxon (OTU) possesses a combination of apomorphic and plesiomorphic character states in the context of a particular phylogenetic analysis and considering a particular root (Nixon and Carpenter, 1993). In cladistic analyses, the MPTs are those that have the smaller number of ad hoc hypothesis (i.e., homoplasies), which means that they are the ones with less character-state changes (Farris, 1983; Nixon and Carpenter, 2011). Thus, what the tree topology tells us is that a taxon is more closely related to a second taxon (its sister taxon), a conclusion derived from the observation that they share more apomorphies (synapomorphies) between them than in relation to all other sampled taxa.

\section{If There Are No Transitional Taxa, Is There an Evolutionary Process?}

One might argue that the term 'transitional' is important in order to communicate with non-scientific audiences, or to be used to combat anti-evolutionary rhetoric. Indeed, it might not be trivial for people outside the scientific field of phylogenetics to comprehend that Tiktaalik (Daeschler et al., 2006) shares more apomorphies with tetrapods than it shares with the lungfishes (i.e., Dipnoi). However, if we treat Tiktaalik as a transitional form between lungfishes and tetrapods, we do imply that the evolutionary goal of the Sarcopterygii lineage was to 'produce' a tetrapod (i.e., that evolution is a directional process leading to a specific morphology). This is clearly a case in which a wrong concept of evolution is not solely caused by the way scientific knowledge is transmitted to a general audience, but a case when scientists themselves probably created the misconception. This is often observed in discussions dealing with human evolution, with Homo sapiens being treated as the final evolutionary product of a lineage (sometimes even the final product of all the living beings), and our close relatives treated in a stepwise fashion as our ancestors (see Crisp and Cook, 2005; Zachos, 2016). We know that we are just one of the many branches of the evolutionary history of all the living forms of the planet. In this way, elevating human beings as a special way of life can have negative consequences, and distort or confound our understanding of our very own origins (Nee, 2005; Montgomery, 2012).

The current biodiversity is the result of distinct rates of diversification and extinctions through geological time (e.g., Benton and Emerson, 2007; Meredith et al., 2011; Tarver and Donoghue, 2011). Due to the extinction of some lineages, some of the living animals may seem alien in relation to their closest relatives because of the great morphological disparity between them. This is, for example, the case for cetaceans (dolphins, porpoises, and whales). From a first glance, it might be difficult to conceive a close phylogenetic relationship between a blue whale and a hippopotamus or a cow, or even that a cow is more closely related to a blue whale than it is to a horse (see Mere- 
dith et al., 2011). However, the fossil record clearly shows the existence of animals with a mix of 'cow- and whale-like' features (Thewissen et al., 2009). These animals with a mosaic of features have been constantly called 'the transitional forms' or 'ancestor forms' (e.g., Yates et al., 2010). As demonstrated above, this is wrong and misleading, as those extinct taxa are in reality neither.

Time is probably the most important 'factor' in the field of palaeontology (and also in Cladistics - see Hennig, 1965). It is known that observations on the current biodiversity, or in the diversity of fossils from a single point in geological time, without taking temporal contexts into account, will provide an incomplete understanding of life (Benton and Emerson, 2007; Tarver and Donoghue, 2011). After all, biological evolution happens through time (Laland et al., 2015), and therefore it is a dimension that cannot be ignored. The fossil record gives us an estimative of when a group originated and/or went extinct, when evolutionary events such as diversification occurred, when 'key' morphological features may have first appeared, and, mostly important, the timing of a transformation series. In this sense, rather than using the idea of 'transitional taxa', we can show the morphological evolution across geological time, and the important role that fossils play in that. A new fossil can exhibit a particular combination of features that helps us bridging the morphological 'gaps'. The fossil record is full of taxa such as Pakicetus, Ambulocetus, Rodhocetus, and Basilosaurus, animals which possess 'cow -and whale-like traits' (Thewissen et al., 2009). Likewise, Eosinopteryx, Anchiornis, and Archaeopteryx are examples in the dinosaur lineage (e.g., Foth et al., 2014); Odontochelys and Proganochelys are examples in the turtle lineage (Li et al., 2008); Panderichthys, Tiktaalik, Acanthostega, and Ichthyostega are examples in the tetrapodomorph lineage (Friedman and Brazeau, 2010); comprising just a few examples of taxa that help us trace the evolution of important vertebrate lineages in more detail. Finally, if evolution is regarded as change through time (Laland et al., 2015), then tracing the history of morphological transformations in a cladogram clearly demonstrates the existence of an evolutionary process.

\section{Practical Guidelines}

Based on the issues discussed above, some practical guidelines are presented here that should help to alleviate any misuse or ambiguity regarding what are commonly but incorrectly regarded as 'transitional' or 'basal' taxa.

- Describe relationships on the basis of sister-group relationships and/or following the hierarchical pattern of cladograms: 'the new mammal presented here is the sister taxon of all other therians' (rather than: the 'most basal' Theria); 'our analysis indicates that the new taxon belongs to Dinosauriformes but outside Dinosauria' (rather than: a new basal dinosauriform).

- 'Basal' also introduces ambiguity in communication among scientists. For instance, is a 'basal' theropod a non-avian theropod or a non-tetanuran theropod; or is a 'basal' sauropodomorph a non-sauropodan sauropodomorph or a non-sauropodiform sauropodomorph. Thus, define boundaries in order to avoid ambiguity: non-sauropodan sauropodomorphs, non-avian dinosaurs, non-tetrapodan tetrapodomorphs.

- Taxa have a unique combination of plesiomorphic and apomorphic character states. Thus, present a new taxon showing how it can help scientists bridging the 'gaps' of the fossil record, but not as a 'transitional taxon' or as 'transitional in morphology': 'the new taxon shows a mosaic of features in relation to those found in tetrapods and other sarcopterygians' (rather than: the new transitional tetrapodomorph).

- There is no direction in evolution. One group might be the best-known and most studied group of a certain lineage, but this does not postulate them as the 'final product' of that lineage: 'the biomechanical analysis 
indicates that the new sauropodomorph was a facultative bipedal animal, but its unique combination of plesiomorphic and apomorphic features of the limbs and axial skeleton helps to explain the acquisition of the traits related to the quadrupedal stance of sauropods' (rather than: the new taxon shows that the evolution of sauropodomorphs was driven by the acquisition of characters related to a fully quadrupedal stance).

\section{CONCLUSIONS}

Problematic issues related to the usage of the term 'basal' in studies dealing with living taxa have been widely demonstrated (Crisp and Cook, 2005; Zachos, 2016), and here it is further shown that 'basal', as well as the term 'transitional', has also been inconsistently applied in cladistics studies with extinct taxa. Scientific papers typically represent the primary data that will be later integrated into the knowledge base of a broader audience. Thus, the avoidance of misusing terms and being more clear and explicit as to their definition is a way to diminish problems in communication when transmitting science to those outside the professional scientific community, or even to researchers from the same particular scientific field. Finally, we do not need to use terms that are inaccurate and/or pointless (e.g., a new basal dinosaur, the most basal bird, a new transitional whale) in order to make fossil discoveries more attractive to journals or to the media. Fossils with a mosaic of features and which help us to fill the gaps in our knowledge on the evolution of a group are already interesting enough without embellishing their phylogenetic status.

\section{ACKNOWLEDGEMENTS}

The author of this study is funded by the program Ciência sem Fronteiras (Science without borders) of CNPq (Process: 246610/2012-3), Brazil. I am thankful to P.L. Godoy (University of Birmingham, UK), F. Montefeltro (IBRC - UNESP, Brazil), F. Quinteiro (FFCLRP - USP, Brazil), G. Ferreira (FFCLRP - USP, Brazil), E. Almeida (FFCLRP - USP, Brazil), M.C. Langer (FFCLRP - USP, Brazil), M.C. de Castro (FFCLRP - USP, Brazil), O.W.M. Rauhut (BSPG, LMU, Germany), S.D. Smith (University of Colorado, US), and J. Tennant (Imperial College London, UK) for critical reviews on early drafts of this manuscript. I also thank the reviewers F. Zachos and S. Nesbitt for their thorough review and highly appreciate the comments and suggestions. All of them significantly contributed to improving the quality of the publication but are at no circumstance responsible for any problematic issue that this manuscript may contain.

\section{REFERENCES}

Baum, D.A., Smith, S.D., and Donovan, S.S.S. 2005. The tree thinking challenge. Science, 310:979-980.

Benton, M.J. and Emerson, B.C. 2007. How did life become so diverse? The dynamics of diversification according to the fossil record and molecular phylogenetics. Palaeontology, 50:23-40.

Brower, A.V.Z. and de Pinna, M.C.C. 2012. Homology and errors. Cladistics, 28:529-538.

Cabreira, S.F., Kellner, A.W.A., Dias-da-Silva, S., Silva, L.R., Bronzati, M., Marsola J.C.A., Müller, R.T., Bittencourt, J.S., Batista, B.J., Raugust, T., Carrilho, R., Brodt, A., and Langer, M.C. 2016. A unique Late Triassic dinosauromorph assemblage reveals dinosaur ancestral anatomy and diet. Current Biology, 26(22):3090-3095.
Crisp, M.D. and Cook, L.G. 2005. Do early branching lineages signify ancestral traits? Trends in Ecology and Evolution, 20(3):123-128.

Daeschler, E.B., Shubin, N.H., and Jenkins Jr., F.A. 2006. A Devonian tetrapod-like fish and the evolution of the tetrapod body plan. Nature, 440:757-763.

Farris, J.S. 1983. The logical basis of phylogenetic analysis, p. 7-36. In Platnick, N.I. and Funk, V.A. (eds.), Advances in Cladistics Vol. 2. Columbia University Press, New York.

Foth, C., Tischlinger, H., and Rauhut, O.W.M. 2014. New specimen of Archaeopteryx provides insights into the evolution of pennaceous feathers. Nature, 511:79-82.

Friedman, M. and Brazeau D. 2010. Sequences, stratigraphy and scenarios: what can we say about the fossil record of the earliest tetrapods? Proceedings of the Royal Society B, 278:432-439. 
Galton, P.M. and Upchurch, P. 2004. Prosauropoda, p. 232-258. In Weishampel, D.B., Dodson, P., and Osmólska, H. (eds.), The Dinosauria, second edition. University of California Press, Berkley.

Gauthier, J. 1986. Saurischian monophyly and the origin of birds. Memoirs of the California Academy of Sciences, 8:1-55.

Griffin, C.T. and Nesbitt, S.J. 2016. The femoral ontogeny and long bone histology of the Middle Triassic (?Late Anisian) dinosauriform Asilisaurus kongwe and implications for the growth of early dinosaurs. Journal of Vertebrate Paleontology, 3:e1111224.

Hennig, W. 1965. Phylogenetic systematics. Annual Review of Entomology, 10:97-116.

Hennig, W. 1966. Phylogenetic Systematics. University of Illinois Press, Urbana, IL.

Krell, F.-T. and Cranston, P.S. 2004. Which side of the tree is more basal? Systematic Entomology, 29:279281.

Laland, K.N., Uller, T., Feldman, M.W., Sterelny, K., Müller, G.B., Moczek A., Jablonka, E., and OdlingSmee, J. 2015. The extended evolutionary synthesis: its structure, assumptions and predictions. Proceedings of the Royal Society Biological Sciences, 282:20151019.

Langer, M.C. and Benton, M.J. 2006. Early dinosaurs: a phylogenetic study. Journal of Systematic Palaeontology, 4:309-358.

Langer, M.C., Ezcurra, M.D., Bittencourt, J.S., and Novas, F.E. 2010. The origin and early evolution of dinosaurs. Biological Reviews, 85:55-110.

Li, C., Wu, X-C., Rieppel, O., Wang, L.T., and Zhao, L.J. 2008. An ancestral turtle from the Late Triassic of southwestern China. Nature, 456:497-501.

Lloyd, G.T., Davis, K.E., Pisani, D., Tarver, J.E., Ruta, M., Sakamoto, M., Hone, D.W.W., Jennings, R., and Benton, M.J. 2008. Dinosaurs and the Cretaceous terrestrial revolution. Proceedings of the Royal Society Biological Sciences, 275:2483-2490.

Longrich, N.R., Bhullar, B.-A.S., and Gauthier, J.A. 2012. A transitional snake from the Late Cretaceous Period of North America. Nature, 488:205-208.

Martinez, R.N., Sereno, P.C., Alcober, O.A., Colombi, C.E., Renne, P.R., Montanez, I.P., and Currie, B.S. 2011. A basal dinosaur from the dawn of the dinosaur era in Southwestern Pangaea. Science, 331:206210.

McPhee, B.W., Yates, A.M., Choiniere, J.N., and Abdala, F. 2014. The complete anatomy and phylogenetic relationships of Antetonitrus longiceps (Sauropodiformes, Dinosauria): implications for the origins of Sauropoda. Zoological Journal of the Linnean Society, 171:151-205.

Meredith, R.W., Janecka, J.E., Gatesy, J., Ryder, O.A., Fisher, C.A., Teeling, E.C., Goodbla, A., Eizirik, E., Simão, T.L.L., Stadler, T., Rabosky, D.L., Honeycutt, R.L., Flynn, J.J., Ingram, C.M., Steiner, C., Williams, T.L., Robinson, T.J., Burk-Herrick, A., Westerman, M., Ayoub, N.A., Springer, M.S., and Murphy, W.J.
2011. Impacts of the cretaceous terrestrial revolution and $\mathrm{KPg}$ extinction on mammal diversification. Science, 334:521-524.

Montgomery, D.R. 2012. The evolution of creationism. GSA Today, 22:4-9.

Nee, S. 2005. The great chain of being. Nature, 435:429. Nixon, K.C. and Carpenter, J.M. 1993. On outgroups. Cladistics, 9(4):413-426.

Nixon, K.C. and Carpenter, J.M. 2011. On homology. Cladistics, 28(2):160-169.

Omland, K.E., Cook, L.G., and Crisp, M.D. 2008. Tree thinking for all biology: the problem with reading phylogenies as ladders of progress. Bioessays, 30(9):854-67.

Otero, A. and Salgado, L. 2015. El registro de Sauropodomorpha (Dinosauria) de la Argentina. Publicación Electrónica de la Asociación Paleontológica Argentina, 15(1):69-89.

Pinheiro, F.L., Franca, M.A.G., Lacerda, M.B., Butler, R.J., and Schultz, C.L. 2016. An exceptional fossil skull from South America and the origins of the archosauriform radiation. Scientific Reports, 6:22817.

Peyre de Fabrègues, C., Allain, R., and Barriel, V. 2015. Root causes of phylogenetic incongruence observed within basal sauropodomorph interrelationships. Zoological Journal of the Linnean Society, 175(3):569586.

Sander, P.M., Christian, A., Clauss, M., Fechner, R., Gee, C.T., Griebeler, E.M., Gunga, H.-C., Hummel, J., Mallison, H., Perry, S., Preuschoft, H., Rauhut, O.W.M., Remes, K., Tütken, T., Wings, O., and Witzel, U. 2011. Biology of the sauropod dinosaurs: the evolution of gigantism. Biological Reviews, 86:117155.

Salgado, L., Coria, R.A., and Calvo, J.O. 1997. Evolution of titanosaurid sauropods. I: Phylogenetic analysis based on the postcranial evidence. Ameghiniana, 34(1):3-32.

Schmidt-Lebuhn, A.N. 2012. Fallacies and false premises-a critical assessment of the arguments for the recognition of paraphyletic taxa in botany. Cladistics, 28(2):174-187.

Sereno, P.C. 1989. Prosauropod monophyly and basal sauropodomorph phylogeny. Journal of Vertebrate Palaeontology, 9(suppl. 3):38A.

Sues, H.-D., Nesbitt, S.J., Berman, D.S., and Henrici, A.C. 2011. A late-surviving basal theropod dinosaur from the latest Triassic of North America. Proceedings of the Royal Society Biological Sciences, 278:3459-3464.

Tarver, J.E. and Donoghue, P.C. 2011. The trouble with topology: Phylogenies without fossils provide a revisionist perspective of evolutionary history in topological analyses of diversity. Systematic Biology, 60(5):700-712.

Thewissen, J.G.M., Cooper, L.N., George, J.C., and Bajpai S. 2009. From land to water: The origin of 
whales, dolphins, and porpoises. Evolution: Education and Outreach, 2:272-288.

Wang, M., Wang, X., Wang, Y., and Zhou, Z. 2016. A new basal bird from China with implications for morphological diversity in early birds. Scientific Reports, 6:19700.

Xu, X., Norell, M.-A., Kuang, X., Wang, X., Zhao, Q., and Jia C. 2014. Basal tyrannosauroids from China and evidence for protofeathers in tyranossauroids. Nature, 431:680-684.

Yates, A.M., Bonnan, M.F., Nevelling, J., Chinsamy, A., and Blackbeard, M. G. 2010. A new transitional sauropodomorph dinosaur from the Early Jurassic of
South Africa and the evolution of sauropod feeding and quadrupedalism. Proceedings of the Royal Society Biological Sciences, 277:787-794.

Zachos, F.E. 2016. Tree thinking and species delimitation: Guidelines for taxonomy and phylogenetic terminology. Mammalian Biology, 81:185-188.

Zanno, L.E., Drymala, S., Nesbitt, S.J., and Schneider, V.P. 2015. Early crocodylomorph increases top tier predator diversity during rise of dinosaurs. Scientific Reports, 5:9276.

Zhou, Z. and Zhang, F. 2002. A long-tailed, seed-eating bird from the Early Cretaceous of China. Nature, 418:405-409. 